Supporting Information for the article

\title{
Concentration Depth Profile-based Multilayer Sorption Surface Tension Model for Aqueous Solutions
}

\author{
Shihao Liu ${ }^{1}$,Cari Dutcher2,*(cdutcher@umn.edu) \\ ${ }^{1}$ Department of Mechanical Engineering, University of Minnesota, Twin Cities, Minneapolis, \\ Minnesota 55455, USA \\ ${ }^{2}$ Department of Mechanical Engineering, Department of Chemical Engineering and Materials \\ Science, University of Minnesota, Twin Cities, Minneapolis, Minnesota 55455, USA
}

\section{Molecule density distribution and energy parameters for more salts}
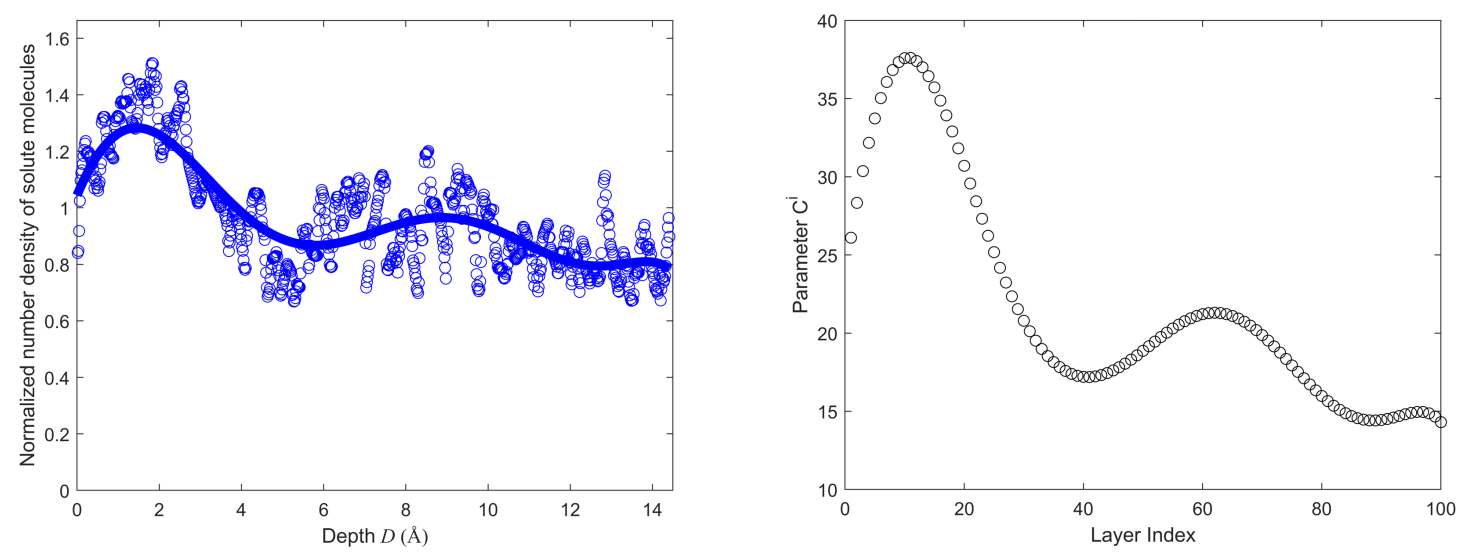

Figure S1-1 (a)The change of molecule number density with depth near the surface for $1.2 \mathrm{M}$ $\mathrm{NaBr}$ aqueous solution based on published data ${ }^{1}$. Polynomial order fitting data points (blue unfilled circle) is 7. (b) Parameter $C^{i}$ for $\mathrm{NaBr}$ at 100 surface layers. 

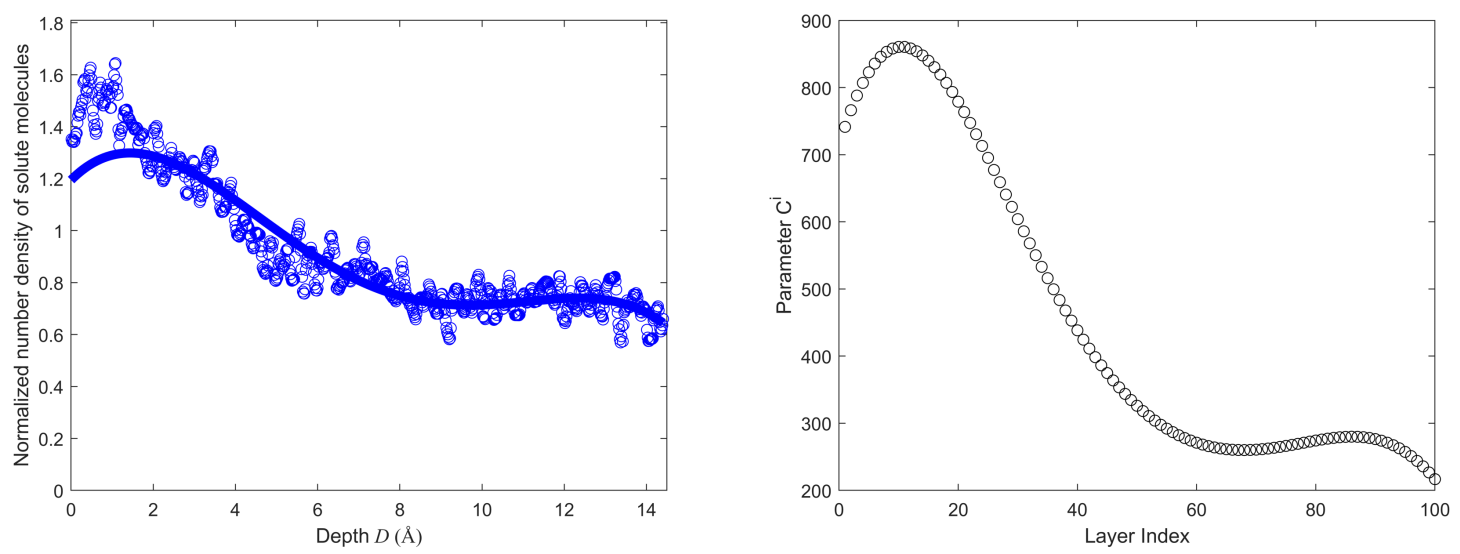

Figure S1-2 (a)The change of molecule number density with depth near the surface for $1.2 \mathrm{M}$ $\mathrm{NaI}$ aqueous solution based on published data ${ }^{1}$. Polynomial order fitting data points (blue unfilled circle) is 4. (b) Parameter $C^{i}$ for $\mathrm{NaI}$ at 100 surface layers.
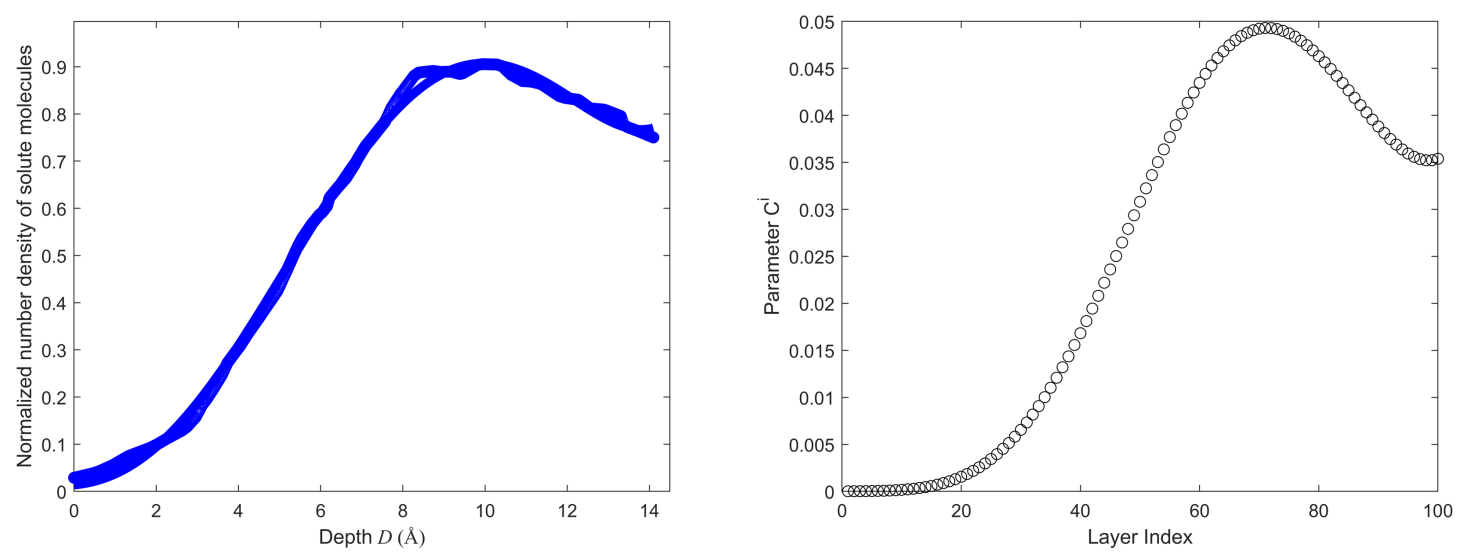

Figure S1-3 (a)The change of molecule number density with depth near the surface for $1.5 \mathrm{M}$ $\mathrm{NaNO}_{3}$ aqueous solution based on published data ${ }^{2}$. Polynomial order fitting data points (blue unfilled circle) is 5. (b) Parameter $C^{i}$ for $\mathrm{NaNO}_{3}$ at 100 surface layers.
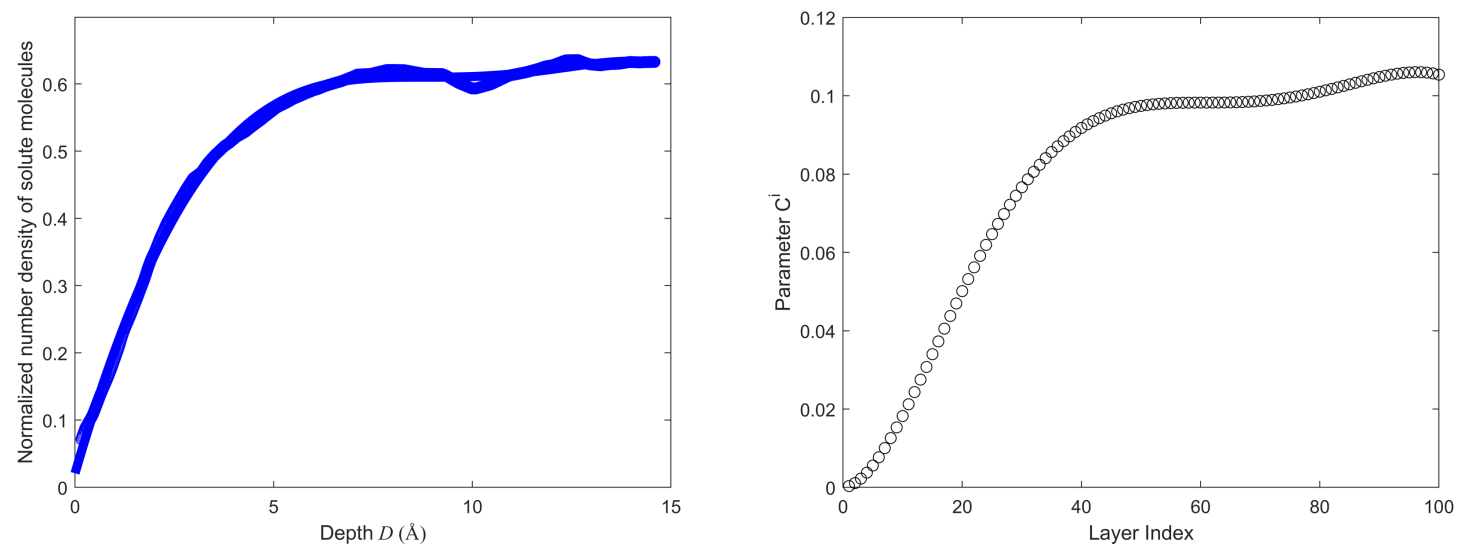

Figure S1-4 (a)The change of molecule number density with depth near the surface for $10 \%$ (mole fraction) $\mathrm{RbCl}$ aqueous solution based on published data ${ }^{3}$. Polynomial order fitting data points (blue unfilled circle) is 5. (b) Parameter $C^{i}$ for $\mathrm{RbCl}$ at 100 surface layers. 


\section{Surface tension prediction of more solutes}

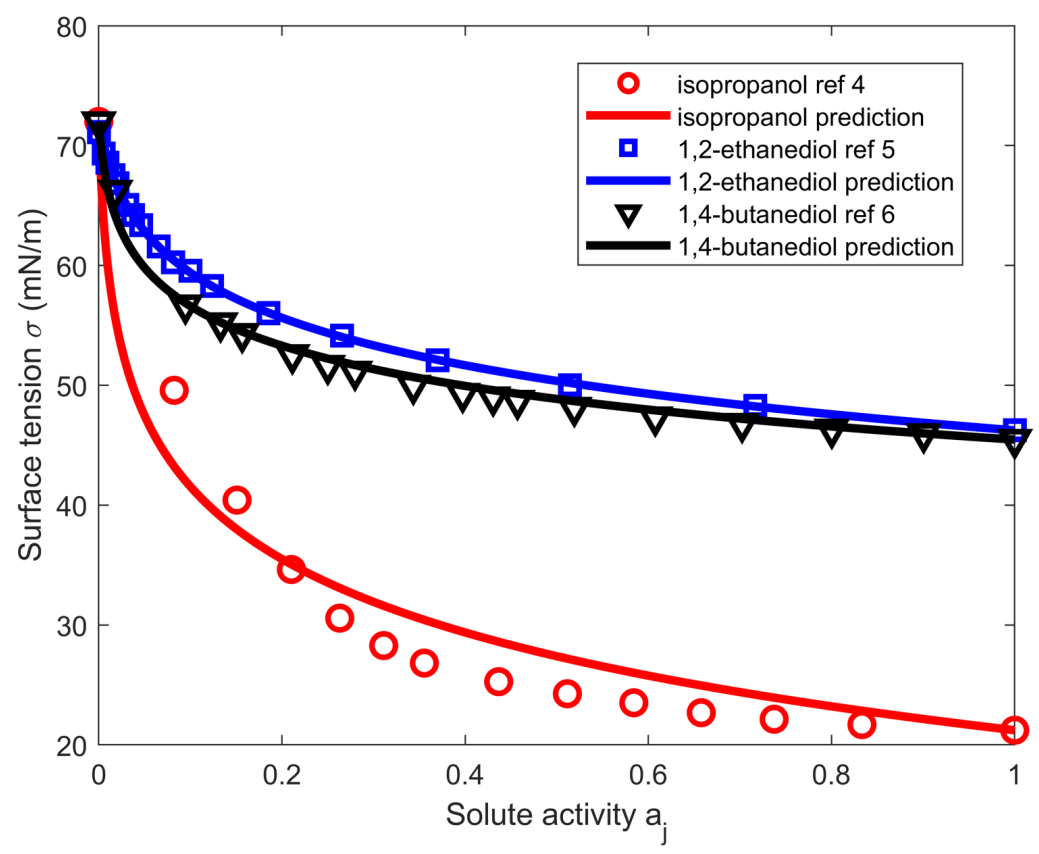

Figure S2-1. Surface tension predictions based on equation (18) from paper manuscript for isopropanol, 1,2-ethanediol and 1,4-butanediol using published data ${ }^{4-6}$.

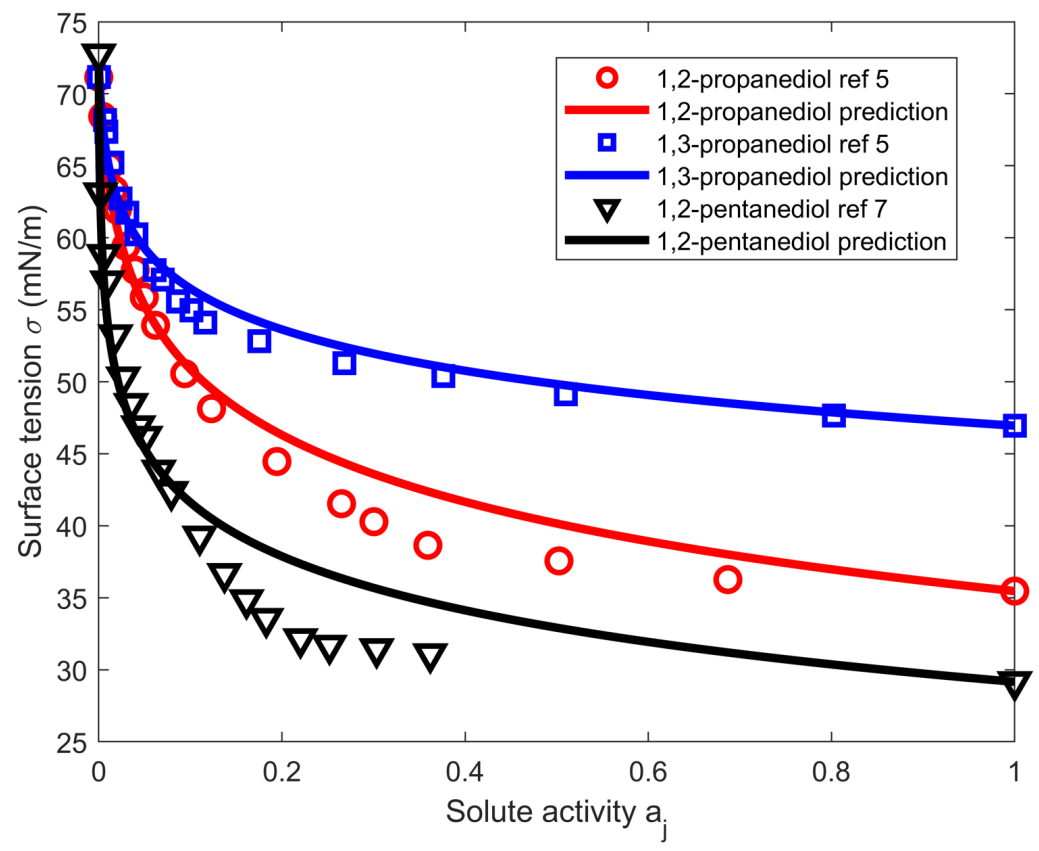

Figure S2-2. Surface tension predictions based on equation (18) from paper manuscript for 1,2-propanediol, 1,3-propanediol and 1,2-pentanediol using published data ${ }^{5,7}$. 


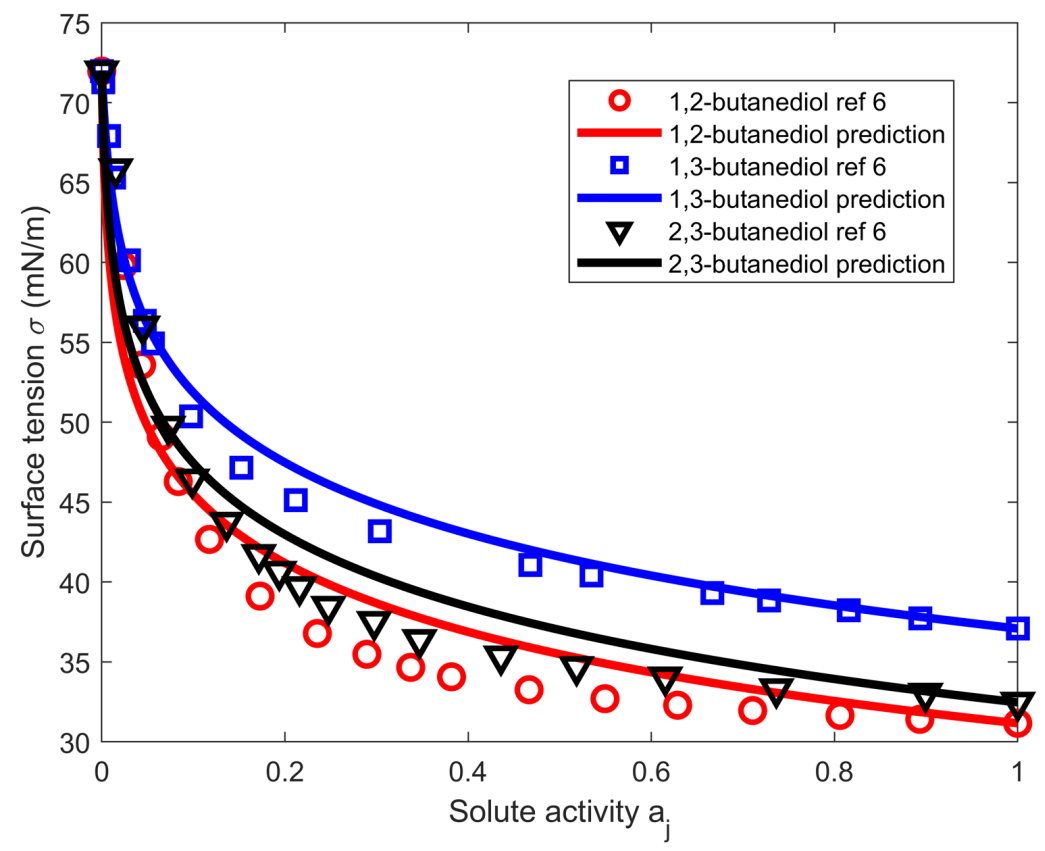

Figure S2-3. Surface tension predictions based on equation (18) from paper manuscript for 1,2-butanediol, 1,3-butanediol and 2,3-butanediol using published data ${ }^{6}$.

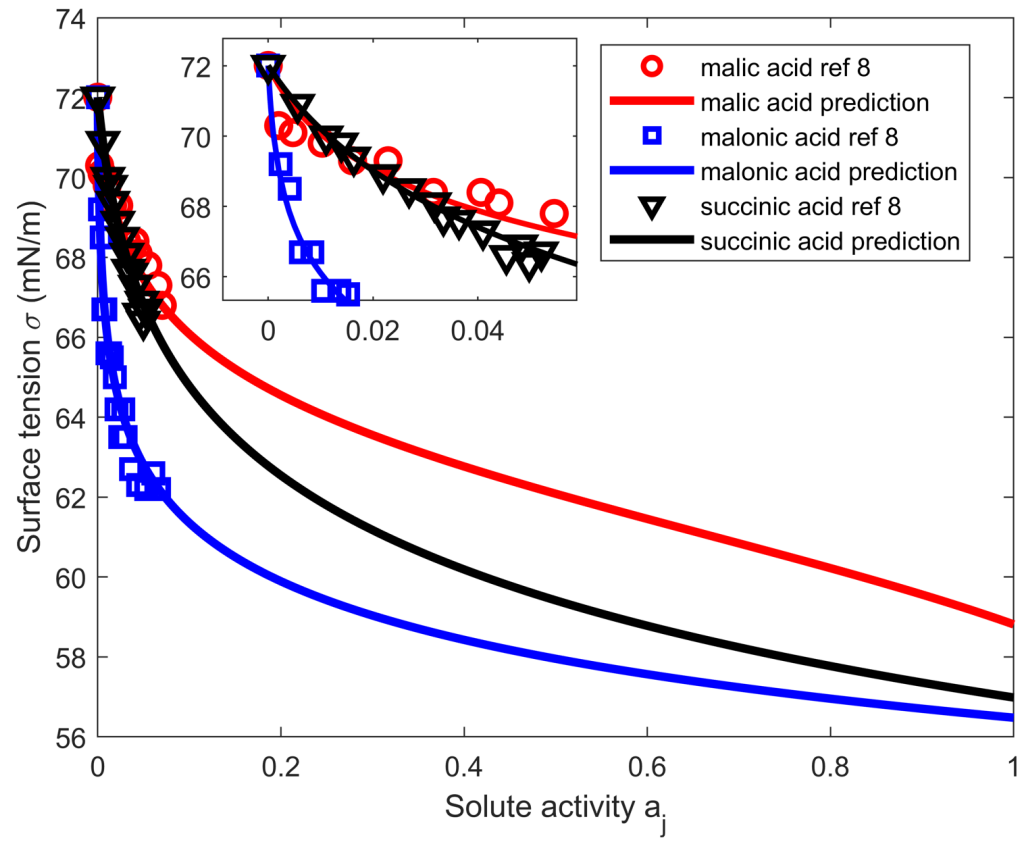

Figure S2-4. Surface tension predictions based on equation (18) from paper manuscript for inorganic salt solutions, including malic acid, malonic acid and succinic acid ${ }^{8}$. Subplots inside the figure (plotted using 'magnify.m' available at MathWorks File Exchange ${ }^{9}$ ) are used to clearly present surface tension-solute activity relationship at small activity values. 


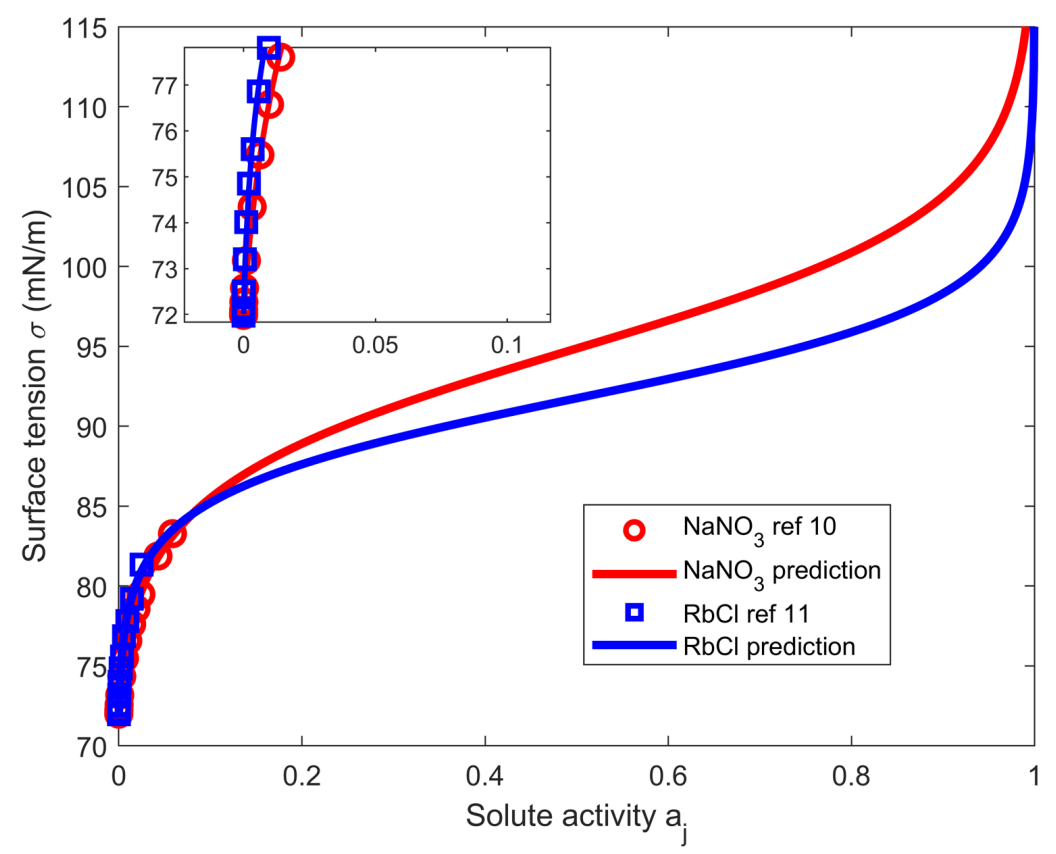

Figure S2-5. Surface tension predictions based on equation (18) from paper manuscript for inorganic salt solutions, including $\mathrm{NaNO}_{3}{ }^{10}$ and $\mathrm{RbCl}^{11}$. Subplots inside the figure (plotted using 'magnify.m' available at MathWorks File Exchange ${ }^{9}$ ) are used to clearly present surface tension-solute activity relationship at small activity values.

\section{Distribution of surface molecules for organic solutes}

The data points in Figure S3 are the square of the normalized number density of methanol and water molecules from molecular dynamic simulation ${ }^{12}$. The data are taken from the simulation for $90 \%$ methanol in water. All the number densities are normalized by the first available and nonzero number density value for methanol molecules from surface to bulk. The reason to choose $90 \%$ methanol in water is because this concentration for methanol is the lowest one among all simulations so that it could best fit the whole range of solute concentration. Hyperbolic tangent-controlled function is applied to fit the data points and it worked well for both methanol and water molecules, indicating the correctness of using equation (39) in the paper manuscript to fit molecule number-relevant parameters. Besides, the mole fraction of methanol near the surface using the fitted function is also plotted in Figure S3. The higher 
concentration of methanol near the surface indicates methanol is rich in the surface region.

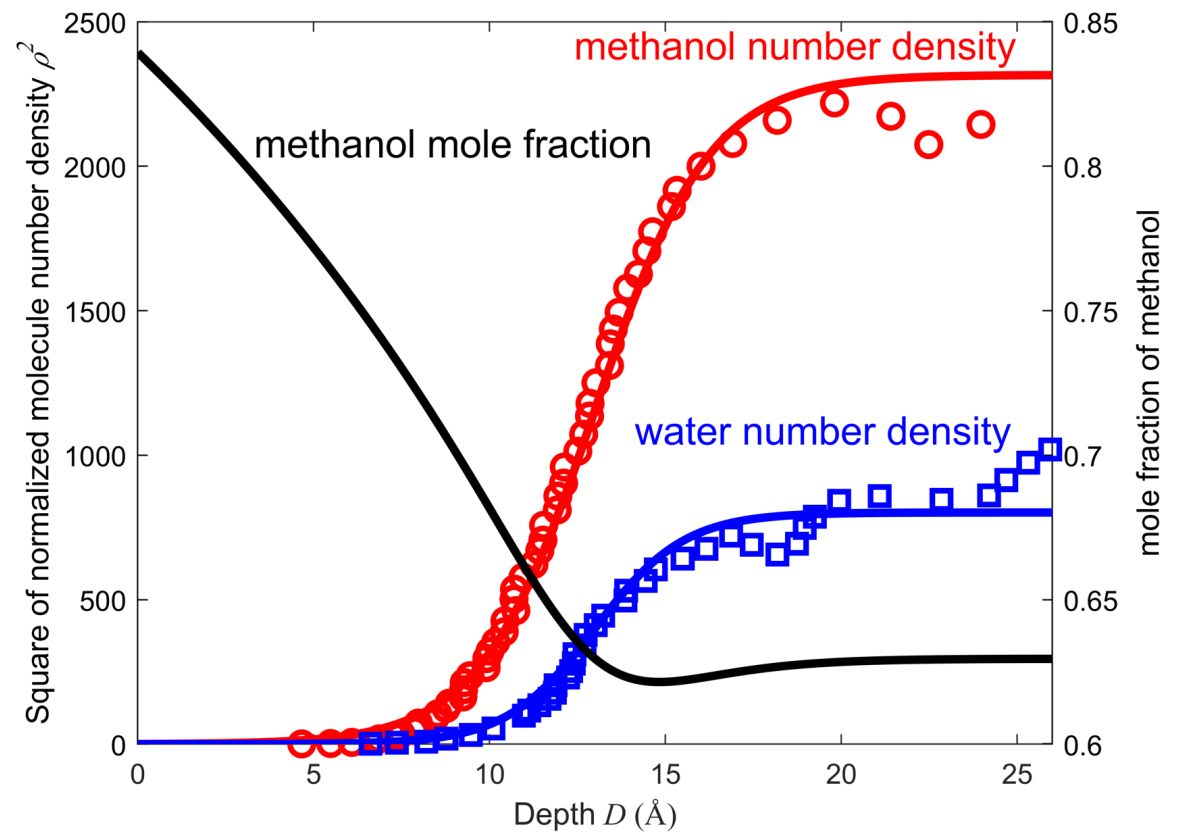

Figure S3. Plots of the square of normalized number densities of methanol (red) and water(blue) molecules as well as the mole fraction of methanol at different depths (black). Data points (circles and squares) are originally from MD simulation ${ }^{12}$ and normalized by the first available and nonzero number density value for methanol molecules. Equation (39) in the paper manuscript is used to fit data points for both methanol and water. Red solid line gives $\rho^{2}=$ $1158 \cdot \tanh (0.3080 \cdot(D-13))+1158$ while blue solid line gives $\rho^{2}=400.9$. $\tanh (0.3944 \cdot(D-13))+400.9$. The number ' 13 ' represents the middle location since the data is taken from 0 to $26 \mu \mathrm{m}$, which is corresponding to $n / 2$ in equation (39) in the paper manuscript which represents the middle sorption layer. The mole fraction of methanol at the surface is calculated using the fitted function for methanol and water molecules. An enrichment of methanol at the surface is observed from the plot.

\section{Parameter fitting procedures for binary solutions}

- Organic solutes

Step 1: Assume an expression for $C^{i}$ based on published concentration depth profile with parameters $W$ and $\Delta C$ as equation (39) in the paper manuscript.

Step 2: Fit $r, W$ and $\Delta C$ using surface tension data versus solute concentration. In the meantime, calculate $K$ using equation (38) in the paper manuscript.

- Inorganic salts

Step 1: Fit $K, r$ and $C^{\prime}$ using surface tension data versus solute concentration, where $C^{\prime}=\sum_{i=1, j=1}^{n} \sqrt{C^{i} C^{j}}$. 
Step 2: Calculate all $C^{i}$ based on the relative magnitude of $N_{S S}^{i}{ }^{2}$ using MD simulation results.

\section{Reference}

(1) Jungwirth, P.; Tobias, D. J. Specific Ion Effects at the Air/Water Interface. Chem. Rev. 2006, 106 (4), 1259-1281. https://doi.org/10.1021/cr0403741.

(2) Thomas, J. L.; Roeselová, M.; Dang, L. X.; Tobias, D. J. Molecular Dynamics Simulations of the Solution-Air Interface of Aqueous Sodium Nitrate. J. Phys. Chem. A 2007, 111 (16), 3091-3098. https://doi.org/10.1021/jp0683972.

(3) Cheng, M. H.; Callahan, K. M.; Margarella, A. M.; Tobias, D. J.; Hemminger, J. C.; Bluhm, H.; Krisch, M. J. Ambient Pressure X-Ray Photoelectron Spectroscopy and Molecular Dynamics Simulation Studies of Liquid/Vapor Interfaces of Aqueous $\mathrm{NaCl}$, $\mathrm{RbCl}$, and RbBr Solutions. J. Phys. Chem. C 2012, 116 (7), 4545-4555. https://doi.org/10.1021/jp205500h.

(4) Vazquez, G.; Alvarez, E.; Navaza, J. M. Surface Tension of Alcohol + Water from 20 to $50{ }^{\circ} \mathrm{C}$. J. Chem. Eng. Data 1995, 40 (3), 611-614. https://doi.org/10.1021/je00019a016.

(5) Nakanishi, K.; Matsumoto, T.; Hayatsu, M. Surface Tension of Aqueous Solutions of Some Glycols. J. Chem. Eng. Data 1971, 16 (1), 44-45. https://doi.org/10.1021/je60048a010.

(6) Hawrylak, B.; Andrecyk, S.; Gabriel, C. E.; Gracie, K.; Palepu, R. Viscosity, Surface Tension, and Refractive Index Measurements of Mixtures of Isomeric Butanediols with Water. J. Solution Chem. 1998, 27 (9), 827-841. https://doi.org/10.1023/A:1022681220744.

(7) Gliński, J.; Chavepeyer, G.; Platten, J. K. Surface Properties of Diluted Aqueous Solutions of 1,2-Pentanediol. J. Chem. Phys. 1999, 111 (7), 3233-3236. https://doi.org/10.1016/S0927-7757(00)00701-9.

(8) Hyvärinen, A. P.; Lihavainen, H.; Gaman, A.; Vairila, L.; Ojala, H.; Kulmala, M.; Viisanen, Y. Surface Tensions and Densities of Oxalic, Malonic, Succinic, Maleic, Malic, and Cis-Pinonic Acids. J. Chem. Eng. Data 2006, 51 (1), 255-260. https://doi.org/10.1021/je050366x.

(9) Rick Hindman (2020). magnify (https://www.mathworks.com/matlabcentral/fileexchange/5961-magnify), MATLAB Central File Exchange. Retrieved July 7, 2020. Magnify.

(10) EW Washburn, C. W. International Critical Tables of Numerical Data, Physics, Chemistry, and Technology Vol. 4; McGRAW-HILL BOOK COMPANY: New York, 1928.

(11) Abramzon, A. A.; Gaukhberg, R. D. Surface Tension of Salt Solutions. Zhurnal Prikl. Khimii 1993, 66 (8), 1896-1906.

(12) Darvas, M.; Pártay, L. B.; Jedlovszky, P.; Horvai, G. Computer Simulation and ITIM Analysis of the Surface of Water-Methanol Mixtures Containing Traces of Water. $J$. Mol. Liq. 2010, 153 (1), 88-93. https://doi.org/10.1016/j.molliq.2009.06.004. 